Revista Iberoamericana, Vol. LXXI, Núm. 213, Octubre-Diciembre 2005, 1139-1148

\title{
EL GAUCHO-ESCRITOR, UN HÉROE SIN ATRIBUTOS. UN ESTUDIO DE “ABALLAY” DE ANTONIO DI BENEDETTO
}

\author{
POR \\ Julio Premat \\ Université de Paris 8
}

En este artículo me planteo dos objetivos. Por un lado pretendo analizar un texto y una figura que, quizás, puedan completar una definición más tradicional del héroe nacional: la figura del gaucho, ese héroe imaginario. Para referirme al gaucho en tanto héroe propongo una lectura de un cuento del mendocino Antonio Di Benedetto, “Aballay” (Absurdos 65-96, publicado en 1978 en el exilio pero quizás escrito antes de 1976) texto que actualiza una serie de interrogantes sobre el surgimiento y los alcances de ese personaje heroico. Por otro lado, me interesa preguntarme sobre una especificidad del sistema literario argentino, que impone o supone (que impuso o supuso, ya que el fenómeno acaso esté terminado) “pasar” por la tradición, o por cierto diálogo más o menos conflictivo con ella, para integrarse en ese sistema literario o para definirse en tanto escritor argentino (la tradición, es decir, los avatares de lo popular-gauchesco, objeto de una prolongada serie de debates y reescrituras, desde la generación del Centenario a "El escritor argentino y la tradición” de Jorge Luis Borges). En este sentido la figura y la trayectoria de Di Benedetto son particularmente significativas por lo marginales: nada anunciaba que el mendocino iba a escribir, prácticamente al final de su producción, un texto que no solo dialoga con una filiación ficcional y problematizadora de la figura del gaucho, sino que además “cierra” cierto tipo de ficciones al respecto. Y no solo que cierra sino que pasa, vertiginosamente, del egocentrismo pulsional y de la tensión experimental de la producción anterior de Di Benedetto, a un sistema muy marcado de reescrituras, y esto sin solución de continuidad. En 1976, en la frontera con el anacronismo, el cuento retoma, dramatizándola, una figura mítica del autor argentino: ser escritor es ser gaucho. Y ser gaucho es una manera errada, casual, periférica, de ser héroe y de ser argentino. Después de una lectura de las diferentes facetas de lo heroico-gauchesco en "Aballay" pretendo analizar las condiciones culturales e imaginarias de esta irrupción de lo pampeano en una obra ajena a ese condicionamiento histórico-literario.

\section{Aballay, EL GAUCHO EXPIATORIO}

El punto de partida de la intriga es un duelo, anterior al tiempo de la historia, en el cual Aballay mata a un hombre y guarda en la memoria la mirada acusadora del hijo de este. Una referencia hecha al pasar por un predicador en la pampa lo va llevar a imitar el 
ascetismo de los estilitas de la antigüedad: en vez de subirse a las columnas que quedaron después de la destrucción de los templos paganos, Aballay va a subirse "para siempre” a su caballo y va a expiar su culpa con una vida de sacrificios y de largos recorridos por la pampa. En algún momento, y huyendo de las patrullas de soldados, debe internarse "tierra adentro”, del otro lado de la frontera, en el mundo de los indios. Su regreso es el inicio de una transformación involuntaria y paradójica: le van naciendo "mitos”, "historias”, y la gente termina tomándolo por un santo; casi involuntariamente, él mismo se adapta a su papel de "hombre-caballo" puro, sin que el malentendido sobre la santidad calme los reclamos de su conciencia, hasta que el hijo del muerto, ya hombre, le sale al encuentro y lo desafía a un segundo duelo, simétrico al primero. Aballay, fatalmente, vuelve a matar y, al bajar por fin del caballo para ayudar al herido, muere él también.

La expiación de este gaucho criminal proviene de un relato y de una palabra. Aballay oye, en un sermón, una palabra que trae consigo una figura de expiación de pecados y una tradición, ajena pero ejemplificadora, ajena pero reutilizable para resolver los conflictos de ese presente (el cuento está situado en la pampa del siglo XIX, en algún momento impreciso después de la muerte de Facundo Quiroga). Esa palabra es “estilita” (“En el sermón de la tarde, el fraile ha dicho una palabra bien difícil, que Aballay no supo conservar, sobre los santos que se montaban a una pilastra”, así empieza el cuento). Efectivamente, un cura de campo menciona, con valor ejemplificador, a esa corriente mística del cercano oriente, la de ermitaños que se instalaban sobre una columna o un pilar y permanecían allí, subsistiendo en medio de privaciones, emblemas vívidos de un sufrimiento encaramado sobre las ruinas del pasado glorioso y rechazado: el del paganismo grecolatino. ${ }^{1}$ Aballay, a partir de esa palabra, traduce, establece equivalencias y toma una decisión magnífica: la de volverse él mismo estilita, es decir, en términos pampeanos, no bajar nunca más de su caballo, convertirse en una reproducción gauchesca de ese ejemplo insigne, de esa palabra revelada. Al hacerlo, Aballay intenta compulsivamente alejarse del determinismo telúrico de la tierra sin límites, arcaica, bárbara, refugiándose en la cultura, en la espiritualidad, en un relato mítico preexistente. El argumento del cuento consiste, a grandes líneas, en dar cuenta de la dificultad y de la posibilidad en sí de esa curiosa manera de vida; y el desarrollo de esta idea central lleva a visitar varias peripecias, espacios y tópicos de la literatura gauchesca o pampeana: encontramos referencias al Facundo (o a Facundo Quiroga, el personaje histórico) en los primeros párrafos, varias anécdotas que demuestran temor de los militares y problemas con la justicia, episodios del refugio en el desierto o de la riña de gallos, la sistemática identificación del gaucho con sus caballos, acciones que suceden a menudo en ranchos y pulperías, alusiones al valor despectivo de la palabra "gaucho" en ese entonces, etc. Sarmiento, Hernández y Güiraldes, por lo menos, aparecen como las "sombras terribles" de la escritura de "Aballay”. Al final del relato, el protagonista regresa al punto de partida. Allí lo espera ese encuentro tan sorpresivo como previsible; el gaucho estilita se topa entonces con el hijo del muerto que, veinte años después, se ha convertido también en una especie de anacoreta, pero anacoreta de la venganza ya que el hombre lo sigue para cobrarle la muerte de su padre.

${ }^{1}$ La visión del anacoreta viviendo en las ruinas del templo clásico es la que da Di Benedetto en el cuento. En la realidad histórica, las columnas o pilares se construían para la instalación de los estilitas (Escolan). 
Símbolo de la culpa y de la redención, Aballay es, como puede verse, un gaucho expiatorio. Es decir, un gaucho responsable de una muerte causada en un duelo (como lo era Martín Fierro), pero torturado por la culpa. Es un gaucho que integra, entonces, la dimensión ética que a menudo Borges comentó en su lectura del poema de Hernández, señalando que la figura elegida como antepasado colectivo de los argentinos era un asesino. Aballay es un Martín Fierro culpable (es decir, un Martín Fierro leído por Borges), pero consciente de la culpa e inscrito en una perspectiva de redención. En este sentido, y a diferencia del payador, el estilita sí sería un antepasado posible. En todo caso, su regreso y el segundo duelo retoman también el desenlace del Martín Fierro, en el cual un nuevo duelo, de payadas esta vez, enfrenta al protagonista con el hermano del Moreno asesinado otrora (y recuérdese que Rojas, en la segunda “pelea”, ya leía, significativamente, la voz de la conciencia, Borges y Guerrero). Borges en su momento había prolongado, en "El fin”, el desenlace del poema de Hernández; en ese cuento de Ficciones, siete años después de la payada, Martín Fierro vuelve a enfrentarse con el hermano del muerto y muere, por supuesto; pero al cumplir su propio destino (al cerrarse la biografía de Martín Fierro, dejada abierta por Hernández), él le transmite involuntariamente al otro Moreno su propio destino de asesino y de gaucho perseguido(Sarlo Borges 85-93). La reescritura propuesta por Borges ignora la transformación del duelo en payada y la dimensión didáctica (y hasta moralizadora) de La vuelta de Martín Fierro (Ludmer 296-315). En la versión de Di Benedetto, el duelo no produce, como el cuento de Borges, una repetición o una reproducción de destinos: no es el hijo el que mata para convertirse en un nuevo culpable, sino que Aballay, sin quererlo, repite su gesto asesino (mata al hijo después de haber matado al padre), y él mismo termina su recorrido de expiación recibiendo una herida mortal en el momento en que decide bajar del caballo para socorrer al hombre agonizante. Hay, por lo tanto, una especie de anulación ética, una fatalidad de la verticalidad negativa; la repetición indica la falta de libre albedrío en el comportamiento del gaucho y lo ineluctable de esa repetición que, desde el inicio, Aballay pretende evitar. La tierra bárbara termina, con un pesimismo digno de Ezequiel Martínez Estrada y de su visión apocalíptica de la pampa, tragándose al gaucho mártir.

Nótese que el texto parece avanzar, por momentos, a partir del discurso del cura: por asociación de palabras: "El fraile dijo que montaban a la columna. El, Aballay, es hombre de a caballo. Tempranito, a los primeros colores del día, Aballay monta en su alazán” (72); tomando ese discurso como ejemplo: "En adelante debió socorrerse con imaginación y ahí donde la astucia fallaba o vislumbraba riesgo de quebrantar su designio, tomaba enseñanza del relato del cura” (73); o tomándolo como un intertexto enigmático que se interroga: “No abusa de la licencia por causa de extrema necesidad o fuerza mayor [...] que creyó sobreentender de los ejemplos del cura” (76), “Toma referencia de las ilustraciones del cura, cuando le contó de aquellos arrepentidos de los tiempos de antes que, si iban a dar al desierto, no todo era miel para ellos: de comer arañas y hasta víboras habló” (78). Este constante interrogar un discurso anterior, cifrado y determinante, se agudiza al final del cuento; al hacerlo, el desenlace plantea también una filiación trágica, gracias a su dramatización ética de la acción. Aballay hiere al hombre con una caña que, por accidente, se ha vuelto afilada (la caña se incrusta en la boca del retador y se la destroza). Entonces se plantea para el gaucho un dilema: ¿puede o no desmontar?, dilema que amplifica un 
interrogante constante a lo largo del texto sobre la norma de su conducta, sobre lo acertado del comportamiento del protagonista, comparado siempre con las explicaciones liminares del cura:

Desmonta a dar socorro y llega hasta el vencido, pero lo bloquea su ley: no bajar al suelo, y lo ha hecho.

Angustiado, levanta la mirada para consultar, y por su cuenta resuelve que en esta ocasión será justo que permanezca todo lo que haga falta. (93)

Esa duda, ese interrogante formulado a la palabra paterna, a la tradición, al pasado, a Dios, le es fatal: "El instante de vacilación basta para que el vengador de abajo alce de punta el cuchillo y le abra el vientre” (93). Si la tragedia griega presenta al hombre en situación de actuar, ubicándolo frente a una decisión que compromete su destino; si esa acción define al héroe trágico como un agente a su vez actuado, culpable e inocente, lúcido y ciego al mismo tiempo, Aballay sería también la reproducción telúrica de otros dilemas, de otros interrogantes sobre las relaciones del hombre con sus actos, dilemas e interrogantes que se definen en el nacimiento del género.

Otra definición refuerza esta hipotética asociación. Ricardo Piglia recuerda que la tragedia puede verse como un género que establece una tensión entre el héroe y la palabra de los dioses, del oráculo, de los muertos: "La tragedia, como forma, es esa tensión entre una palabra superior y un héroe que tiene con esa palabra una relación personal” (65). Lo que se le plantea a Aballay, en el momento de actuar, es un interrogante ético sin respuesta, un dilema sin solución, pero que remite a un discurso heredado, a una visión tradicional del mundo. La palabra del cura (los estilitas y el conjunto normativo que se esboza detrás de esa denominación), ¿qué quiere decir exactamente? ¿Cómo interpretarla? ¿Cuál es la norma? ¿Cómo actuar? Este sería el primer segmento de una larga serie de preguntas que la reescritura de la reescritura borgeana del Martín Fierro va a ir suscitando. A pesar de “El escritor argentino y la tradición”, la palabra heredada, la palabra aprendida en la cultura occidental, no permite saber cómo actuar, cómo enfrentar las contradicciones de la realidad, cómo definir una posición ética, en Argentina y a mediados de la década del setenta.

Pero, por supuesto, si la gauchesca y las lecturas del Martín Fierro establecen una relación con el concepto de héroe, este sería el héroe de la épica, el fundador, el realizador de proezas que, gracias a un relato, permite transmitir un mundo total, un saber, una esencia y, para decirlo de manera instrumental, una identidad. La asociación entre el Martín Fierro y la epopeya es, de más está decirlo, fruto de las conocidas y comentadas lecturas de Lugones. La célebre analogía entre el poema de Hernández y los de Homero es un gesto de construcción genérica, de transformación textual, de apropiación. Ampliamente explicables en el contexto y en la perspectiva ideológica de Lugones, estas afirmaciones aparecen también como una paradoja histórica. El gaucho perseguido, menospreciado y marginalizado en la Argentina del xIX, da lugar a un texto de reivindicación y defensa de su estatuto y de su figura que tendrá, como es sabido, una masiva repercusión popular; las anécdotas sobre almacenes de campo que encargaban latas de sardinas y ejemplares de La vuelta de Martín Fierro o las fervorosas lecturas colectivas que se 
organizaban en lugares recónditos de la pampa pertenecen a las leyendas que rodean el texto. Un relato que cambia la realidad podría decirse borgeanamente, o hacerlo citando a Martínez Estrada: "La realidad misma de nuestras llanuras parece convertirse en un plagio del Poema, y sus hombres oriundos adquieren sus dichos y hasta sus costumbres" (Martínez Estrada 263). El hecho de que ese texto se convirtiera en el emblema de la nacionalidad cuando los gauchos han desaparecido del escenario político y económico del país, se convirtiera en el emblema de la nacionalidad, es un conocido ejemplo de la arbitrariedad del concepto de libro fundador, o de su definición compulsiva en Argentina. Entre la intencionalidad eventual de Hernández, la repercusión de su obra y su contradictoria “canonización” por la generación del Centenario, una serie curiosa de inversiones, muy comentadas por supuesto, acompañan el texto. Muerte y transfiguración de Martín Fierro, decía también Martínez Estrada.

Ahora bien, esta historia, la historia del devenir del texto y de esa figura, la del gaucho perseguido convertido en santo laico para una sociedad transformada por el aluvión inmigratorio es, también, la historia narrada en el cuento de Di Benedetto. Aballay se irá volviendo, a pesar suyo, un objeto de culto y veneración. Desde ya, las resonancias grecolatinas del ejemplo de los estilitas sugieren ecos con la lectura épica del gaucho y del Martín Fierro por Lugones. Es de notar, en esta perspectiva, que los indios que Aballay encuentra durante su vida retirada piensan que no es que él no quiera sino que no puede desmontar, y deducen, por lo tanto, que se trata de un "hombre-caballo", es decir, de un Centauro (75). En el cuento, la mirada de los indios, integra irónicamente el gaucho perseguido al Olimpo de los griegos. Una serie de peripecias de la trayectoria del gaucho estilita impone una lectura en ese sentido, es decir, el de la emergencia de un héroe nacional gracias a un malentendido. Porque, anecdóticamente, es un malentendido el que origina la transformación a la que aludo. Aballay gana una apuesta y el perdedor, resentido, le paga tirándole las monedas al piso, al pie del caballo. El jinete, para evitar la humillación de pedir ayuda y lo ridículo del gesto de intentar recuperarlas él mismo, prefiere renunciar a un dinero que en realidad está necesitando y hasta codiciando. Ese gesto, malinterpretado ya que no corresponde a un desprendimiento voluntario, es el punto de partida de una particular reputación: "Desde entonces, por ese gesto, para los testigos nada fácil de descifrar y que tendría relación con el desprendimiento, a Aballay le nacen famas” (75). Luego, cuando regresa de una difícil estadía en la "bruta pampa”, sucio, menesteroso, sediento, su decadencia física da lugar, de nuevo, a una interpretación errada: "No lo reconocen a él, nunca lo vieron; le reconocen sus famas, que le han crecido, sin él saberlo, que son diversas y contradictorias, pero lo realzan dentro de una concepción del bien. 'Lleva su cruz', se susurran, con actitud reverente” (79). Aballay, al oír ese comentario decide construirse una cruz con dos palos y hace abluciones. Empieza a ser reconocido, no en tanto Aballay, sino en tanto imagen de esos relatos anónimos. Aballay se adapta a un personaje creado por la imaginación popular: “Así ocurre, hasta que alguien toma razón del crucifijo y pide parecer a un vecino. ‘¿Será ése que...?’. Hay acuerdo en que puede ser. Van ellos, entonces, a rendir su ofrenda -pan y vino, como principio- a ese peregrino extraño que, según decires, no descabalga nunca” (80). Se ha convertido en santo. Se le ofrece pan y vino, aludiendo a una comunión. Se ha convertido en una traducción del personaje mencionado en el relato del cura como el gaucho Martín Fierro traduciría al Cid 
o a Ulises, en la visión de los intelectuales del Centenario. Finalmente se le piden curaciones milagrosas y a la pregunta “¿quién sos?” contesta, como Cristo en tantos cuentos populares: "un pobre” (87).

Este proceso es la dramatización entonces de un malentendido: el criminal, el excluido, el culpable, se convierte, sin buscarlo, en el centro espiritual de la región. Por supuesto, esta exaltación de un gaucho malo, esta construcción casual de un héroe, ficcionaliza la recepción del Martín Fierro en su momento y la mitificación paradójica de la crítica nacionalista (la transformación del gaucho perseguido en fundador, en antepasado mítico). La historia de Aballay repite el Martín Fierro y multiplica sus eventuales interpretaciones.

Pero lo más notable del relato de Di Benedetto no es en sí esta transcripción ficcional de un proceso cultural, sino un desliz que transforma al héroe -en el sentido épico- en santo y mártir. Si la épica está presente en el relato, solamente lo está por las alusiones veladas a la lectura de Lugones (o a la de Rojas), ya que todo rasgo épico en la historia de Aballay parece borrado. En su lugar, encontramos otro tipo de héroe, otro tipo de relato: una vida de santo. Como la vida de san Antonio y sus variopintas tentaciones, como la de san Simón el viejo, el más célebre estilita de la antigüedad, que pide que le construyan una columna de cuarenta codos para alejarse de su propio prestigio espiritual y de las multitudes de espectadores que asisten a sus actos de contrición, la de Aballay es también una vida de pulsiones, revelación, conversión, privaciones y martirio. El destino del gaucho como una canonización involuntaria; su expiación como un fracaso; su identidad -supuestamente determinante para los argentinos de hoy-, como un malentendido. La ironía que implica convertir al héroe mítico en santón errado es intensa, pero negativa, ya que supone el fracaso, otra vez, de toda referencia ética.

Aballay, gaucho escritor

Ahora bien, esta curiosa historia de un gaucho heroico por descuido, culpable sin quererlo, ermitaño ambulante, descifrador torpe de una palabra heredada, avatar anacrónico de la figura de Martín Fierro ya tan transformada por una red de reescrituras, es, como empecé diciendo, una anomalía dentro del corpus dibenedettiano centrado en otros espacios, preocupaciones y modos de integrarse en el sistema literario argentino. Beatriz Sarlo supone que en la experiencia de todo escritor argentino se encuentra, sin hurgar demasiado, la pampa (Una modernidad... 232), lo que significa, también, que todo escritor de la pampa sería un escritor argentino (por ejemplo Hudson). En Di Benedetto hay que buscar mucho la pampa; escrita desde Mendoza con una voluntaria omisión de Buenos Aires y sus tradiciones culturales, su obra se caracteriza por una serie de desplazamientos en lo que concierne a cierta tradición de oposición pampa/ciudad y civilización/barbarie en la literatura argentina. Por lo pronto, y esto es relativamente anecdótico, en esos textos la ciudad ya no es Buenos Aires sino Mendoza, y la pampa se ha convertido en un verdadero “desierto”, el que rodea esa ciudad argentina. Muchos relatos del autor, en particular algunos que fueron editados o reeditados junto con “Aballay” en el volumen de cuentos Absurdos (me refiero a "Caballo en el salitral”, "El juicio de Dios”, “Pez”, “Felino de Indias” por lo menos), así como algunas páginas de Los 
suicidas, retoman esa oposición entre la ciudad y la no-ciudad como elemento estructurante de la concepción del espacio nacional. Pero la retoman con una fuerte marca imaginaria que desdibuja sus valores culturales: la oposición toma visos de una confrontación entre el yo y el no-yo, entre el mundo consciente y el mundo incontrolado de la indiferenciación amenazante, entre lo humano y lo animal (o entre la razón y una peligrosa animalización del hombre). Fuera de la ciudad, más allá de la casa, de la calle, de la construcción, comienza un espacio arcaico en donde fuerzas incontrolables amenazan los proyectos de progreso humano (es lo que sucede en “El juicio de Dios”), pero que sobre todo ponen en duda la identidad, la conciencia, el control racional sobre un universo regresivo. El paralelo entre la intromisión del ruido desestabilizador en El silenciero, ruido que impide pensar, escribir y finalmente ser, y la irrupción de lo exterior de las ciudades en lo interior de lo urbano es evidente (por un lado la modernidad perturbadora, por el otro lo arcaico destructor). En este sentido se puede entender que Zama, una de las primeras ficciones del escritor y seguramente la más importante de su producción, pase de Mendoza a Asunción, del presente (siglo xx) al período colonial (siglo xvIII) y de la confrontación ciudad/ desierto a otra, ciudad/selva, retomando esta vez una tradición latinoamericana que, de $L a$ vorágine en adelante, transforma el corazón del continente en un antro de anterioridad radical, exuberante y aniquiladora.

O sea que hay un segundo desplazamiento, que sería el paso de lo ideológico-cultural (la propuesta sarmientina y sus peripecias posteriores) a una lectura imaginaria, material, subjetiva del fenómeno. En la serie de textos que marcan la estructuración del mapa argentino en términos literarios, Di Benedetto lee la subjetividad, las proyecciones afectivas, la capacidad de fantasear o soñar el espacio, características presentes en el Facundo y a veces dominantes en Radiografía de la pampa. El espacio de la no-ciudad es ese espacio de la barbarie (Sarmiento), de un determinismo apocalíptico (Martínez Estrada), pero sobre todo es la pantalla de proyección de un universo íntimo. En este sentido “Aballay” implica un retorno al origen, o un remontar, escribiendo, la serie de lecturas que podían rastrearse en las obras precedentes. La pampa de la que trata de alejarse el gaucho estilita gracias a la elevación acumula características negativas que tienen que ver con la pulsión incontrolable (el crimen), la inconsistencia del yo (lo viscoso) y la anterioridad imaginaria (es una tierra "bruta”, atravesada por "rajaduras profundas y anchas" abiertas por “olvidadas correntadas”, 76). La pampa vuelve a ser ese lugar genético, materno, de fuerzas animales desencadenadas, que ya era en Don Segundo Sombra. Como en esa novela, aprender a ser gaucho es aprender a controlar la virulencia de la pampa (es el recorrido de Fabio y el ejemplo que le da su padrino); o es alejarse de la tierra, refugiarse en la espiritualidad, en la palabra paterna, en la altura sufriente, lo que intenta hacer Aballay, siguiendo la palabra de otro "padre”, el cura.

Pero Don Segundo no solo enseña el control de las pulsiones sino que resulta ser un maestro de narraciones; la iniciación también consiste en controlar la impetuosidad del joven para aprender el laconismo, la sabiduría y el control del relato que caracterizan al viejo gaucho, heredero putativo de tantos payadores. Porque, claro está, la pampa es un lugar de identidad y de proyectos ideológicos, pero al mismo tiempo funciona en tanto marco mítico de nacimiento del escritor argentino. Un narrador argentino que sería aquel que se "inventa” una tradición y una identidad, el que se sitúa en el cruce entre pulsión y 
razón, el que se pelea con el vacío pampeano como único lugar heredado, como única página posible desde donde leer y reescribir las bibliotecas europeas. Las coordenadas del espacio literario en Di Benedetto, arriba evocadas, permiten aprehender, creo, la dimensión que toma la pampa en su cuento: el de un decorado que, metonímicamente, significa el lugar de la creación. Lugar de creación, es decir, lugar de cruce de lo imaginario con lo cultural, de lo pulsional con la tradición (o de lecturas imaginarias de lo cultural, de lecturas pulsionales de la tradición).

Ahora cabe recordar que la elección del Martín Fierro como figura heroica por parte de Lugones tiene que ver también con una intención de “estetización de la historia” y una concepción del lugar peculiar que el poeta puede tener en la definición de una nacionalidad. “El idioma es... el elemento más sólido de las nacionalidades” afirma Lugones en el prólogo de su Lunario sentimental (92); los poetas cumplen para él una función social: la de definir, como lo haría un héroe, esa nacionalidad gracias al lenguaje (Montaldo 62-70). Y leemos en El payador: "El poeta es, en gran parte, un agente involuntario de la vida heroica por él mismo revelada” (30). Para Lugones el gaucho Martín Fierro es antes que nada un "payador", es decir un poeta, y es gracias a ese dominio creativo y fundador del lenguaje que él puede “civilizar a la pampa”: ser un héroe. Ese heroísmo que, compulsivamente, Lugones le atribuye al gaucho-escritor (y a sí mismo), del que Güiraldes intenta apropiarse dedicando su novela "Al gaucho que llevo en mí, sacramente, como la custodia lleva la hostia” (66), del acto de escritura, parece derrumbarse en "Aballay”. Si escribir es manchar la hoja en blanco, marcar el cuerpo materno con una palabra a la vez heredada y parricida, escribir en Argentina pasa por la capacidad de dejar una huella en la inmensidad de esa llanura literaria. La actualización de una serie de imágenes heroicas alrededor del gaucho, que recorrimos en la primera parte de este trabajo, tiene que ver, ante todo, con este aspecto. Así como Sarmiento, el sanjuanino, escribe desde el exilio sobre una pampa que no conoce, Di Benedetto, el mendocino que durante muchos años y varios libros buscó su propia originalidad en algunos espectaculares experimentos narrativos (pienso en El pentágono y Declinación y ángel) y que nunca fue reconocido en los centros de legitimación del sistema literario nacional, termina deambulando por el espacio fundador de una literatura, justo antes o justo después de que ese mismo país lo expulse a otro exilio.

$\mathrm{Y}$ es significativo entonces que los diferentes mecanismos de reescritura y las variantes sobre una tradición que hemos analizado estén entremezclados con una representación espacial intensamente subjetiva. Como tantas otras obras (pero seguramente más que muchas otras obras), la de Di Benedetto tiene visos de una autoficción en donde el ser escritor, el poder escribir, el representar el trabajo o las condiciones de emergencia de la escritura, ocupan un lugar importante. Esa tematización de la escritura aparece siempre marcada por la impotencia, las perturbaciones producidas por el deseo, la recurrencia de una culpa de raigambre edípica, la evocación repetida de un padre ausente o de un padre muerto. Ser escritor tiene que ver con una definición ontológica y pulsional, ser escritor tiene que ver con una intensa dramatización de la herencia, herencia de una compulsión al suicidio (en Los suicidas) o herencia de un piano paterno que el hijo no sabe tocar (El silenciero). En este sentido, hay que notar la relación conflictiva que se instala en “Aballay”, desde las primeras páginas, con otros relatos, otras tradiciones: la cultura 
clásica, la tradición cristiana, la gauchesca, sus lecturas e interpretaciones. Desde esta perspectiva, el gaucho Aballay no puede sino interpretar, repetir, releer, reescribir, intentar descifrar correctamente un mensaje heredado y polisémico; y también buscar en esa biblioteca un camino para su propia culpa, para su propio crimen, para su propio destino, para su propia palabra. El intento de purificación (o de glorificación) gracias a la identificación con los modelos es, de por sí, un gesto anacrónico condenado a fracasar: ya no se puede elegir ser ermitaño sobre una columna, ya no se puede inventar nada sobre gauchos y pampa, solo se puede recorrer un laberinto de nombres canonizados y frases ya impresas, leídas e interpretadas. La pampa es incapaz de brindarle al escritor una imagen heroica renovada; el anacronismo aparente termina definiendo coordenadas muy actuales de cierta disolución melancólica de una tradición que ha dejado de ser un concepto operativo. Si el gaucho Don Segundo Sombra resultaba ser un diestro maestro de escritura para Fabio en la novela de Güiraldes, Aballay sólo copia, reproduce, mima. Estilita o estilista, ese lugar elevado sobre una columna, un pilar, un caballo es el emblema del escritor en la versión de Di Benedetto, ermitaño sufriente, instalado en las ruinas de una arquitectura equilibrada y perfecta, de una creencia y una belleza sin fallas, de una escritura a su manera clásica (la de Hernández, la de Lugones, la de Borges), imposible de imitar pero todavía imponente.

El interés de “Aballay” es por lo tanto doble: por un lado cristaliza una concepción de la escritura y una representación del autor presentes en otras obras anteriores de Di Benedetto, enriquecida aquí con el contrapunto heroico propuesto por la tradición pampeana y sus mitos de creación. Por otro lado, ese gaucho mendocino retoma, a mediados de los setenta, un recorrido que comienza con Hernández (y en alguna medida con el Facundo), y se prolonga con los autores citados: Lugones, Rojas, Martínez Estrada, Borges. Más allá de sus implicaciones dentro del corpus de Di Benedetto, el cuento cierra un ciclo o termina con las reescrituras reverenciales o trascendentales del gaucho y de la pampa. O, tal vez, es la última peripecia de una expectativa: la del gaucho-escritor, la de un escritor heroico, heredero y fundador de una tradición. Ya Borges había intentado concluir el proceso, al inventar "El fin" de esa historia con espectaculares operaciones de lectura, pero dejando intersticios: la repetición, la circularidad, la fatalidad. En el momento de la dictadura y en esos intersticios se instala "Aballay", borrando todo futuro: el gaucho como héroe inerte y su vida como símbolo de anulación ética no tendrán más avatares. Simultáneamente, El fiord (1969) de Osvaldo Lamborghini y Moreira de César Aira introducen otros modos, irrespetuosos, paródicos, histriónicos, de referirse a lo popular-gauchesco, modos que se prolongarán en la década del ochenta con varias novelas de Aira (Ema la cautiva, El vestido rosa) y con el irrisorio escritor-payador que resulta ser el personaje de Waldo en La ocasión de Juan José Saer.

Pero este último avatar del gaucho-escritor no carece de paradójica grandeza. Aballay es un héroe pasivo, fruto de una construcción que le es ajena y que se fundamenta en una ausencia, en un vacío, en un silencio. Aballay, héroe triste, observador melancólico de un pasado espléndido, de una escritura sin dificultades. Aballay, el héroe alejado, que renuncia, que se retrae en su propia duda y en su propia culpa, héroe cuyo único acto voluntario es la falta de voluntad (esa decisión de no actuar, lo que no impide que mate nuevamente). Aballay, imagen patética del que sería el último héroe argentino, el escritor, 
al que la sociedad entroniza en un lugar ambiguo, presente y borrado, sabio y mudo, pero que no puede sino contemplar en silencio un mundo sin héroes. El escritor, como el gaucho, sería, entonces, un héroe casual, un héroe sin atributos.

BiBLIOGRAFÍA

Aira, César. Ema la cautiva. Barcelona: Mondadori, 1997. El vestido rosa. Buenos Aires: Ada Korn, 1984. Moreira. Buenos Aires: Achával solo, 1975.

Borges, Jorge Luis. “El fin”. Ficciones. Madrid: Alianza, 1987. 183-7. y Margarita Guerrero. El Martín Fierro. Obras completas en colaboración. Madrid: Alianza, 1983. 65-119.

Di Benedetto, Antonio. Los suicidas. Buenos Aires: Sudamericana, 1969. El silenciero. Buenos Aires: Troquel, 1964. Declinación y ángel. Mendoza: Biblioteca San Martín, 1958. Zama. Buenos Aires: Doble P, 1956. El pentágono. Buenos Aires, Doble P, 1955. “Aballay”. Absurdos. Barcelona: Pomaire, 1978. 65-96.

Escolan, Philippe. "Vivre sur une colonne: le défi des moines stylites”. L'histoire 226 (noviembre 1998): 76-82.

Güiraldes, Ricardo. Don Segundo Sombra. Madrid: Cátedra, 1982.

Lamborghini, Osvaldo. El fiord. Novelas y cuentos. Barcelona: Serbal, 1988. 17-34.

Ludmer, Josefina. El género gauchesco, un tratado sobre la patria. Buenos Aires: Sudamericana, 1988.

Lugones, Leopoldo. Lunario sentimental. Madrid: Cátedra, 1988. El payador. Caracas: Ayacucho, 1979.

Martínez Estrada, Ezequiel. Radiografía de la pampa. Buenos Aires: Losada, 1985. Muerte y transfiguración de Martín Fierro. México: FCE, 1948.

Montaldo, Graciela. De pronto, el campo. Literatura argentina y tradición rural. Rosario: Beatriz Viterbo, 1993.

Piglia, Ricardo. "Los sujetos trágicos (literatura y psicoanálisis)”. Formas breves. Barcelona: Anagrama, 2000. 55-68.

Saer, Juan José. La ocasión. Barcelona: Destino, 1988.

Sarlo, Beatriz. Borges, un escritor en las orillas. Buenos Aires: Ariel, 1995. Una modernidad periférica: Buenos Aires 1920 y 1930. Buenos Aires: Nueva Visión, 1988. 